ARTICLE

\title{
Bimetallic nickel-molybdenum/tungsten nanoalloys for high-efficiency hydrogen oxidation catalysis in alkaline electrolytes
}

Yu Duan1,6, Zi-You Yu1,6, Li Yang 2,3,6, Li-Rong Zheng ${ }^{4}$, Chu-Tian Zhang1, Xiao-Tu Yang1, Fei-Yue Gao', Xiao-Long Zhang (iD ${ }^{1}$, Xingxing Yu ${ }^{1}$, Ren Liu ${ }^{1}$, Hong-He Ding ${ }^{5}$, Chao Gu${ }^{1}$, Xu-Sheng Zheng ${ }^{5}$, Lei Shi ${ }^{1}$, Jun Jiang (1) ${ }^{2}$, Jun-Fa Zhu (i) ${ }^{5}$, Min-Rui Gao (i) ${ }^{1 凶} \&$ Shu-Hong Yu (id ${ }^{1 凶}$

Hydroxide exchange membrane fuel cells offer possibility of adopting platinum-group-metalfree catalysts to negotiate sluggish oxygen reduction reaction. Unfortunately, the ultrafast hydrogen oxidation reaction (HOR) on platinum decreases at least two orders of magnitude by switching the electrolytes from acid to base, causing high platinum-group-metal loadings. Here we show that a nickel-molybdenum nanoalloy with tetragonal $\mathrm{MoNi}_{4}$ phase can catalyze the HOR efficiently in alkaline electrolytes. The catalyst exhibits a high apparent exchange current density of 3.41 milliamperes per square centimeter and operates very stable, which is 1.4 times higher than that of state-of-the-art Pt/C catalyst. With this catalyst, we further demonstrate the capability to tolerate carbon monoxide poisoning. Marked HOR activity was also observed on similarly designed $\mathrm{WNi}_{4}$ catalyst. We attribute this remarkable HOR reactivity to an alloy effect that enables optimum adsorption of hydrogen on nickel and hydroxyl on molybdenum (tungsten), which synergistically promotes the Volmer reaction.

\footnotetext{
${ }^{1}$ Division of Nanomaterials and Chemistry, Hefei National Laboratory for Physical Sciences at the Microscale, Institute of Energy, Hefei Comprehensive National Science Center, CAS Center for Excellence in Nanoscience, Department of Chemistry, Institute of Biomimetic Materials and Chemistry, University of Science and Technology of China, 230026 Hefei, China. ${ }^{2}$ Hefei National Laboratory for Physical Sciences at the Microscale, CAS Center for Excellence in Nanoscience, School of Chemistry and Materials Science, University of Science and Technology of China, 230026 Hefei, China. ${ }^{3}$ Institutes of Physical Science and Information Technology, Anhui University, Hefei, Anhui 230601, China. ${ }^{4}$ Beijing Synchrotron Radiation Facility, Institute of High Energy Physics, Chinese Academy of Sciences, 100049 Beijing, China. ${ }^{5}$ National Synchrotron Radiation Laboratory, University of Science and Technology of China, 230029 Hefei, China. ${ }^{6}$ These authors contributed equally: Yu Duan, Zi-You Yu, Li Yang. ${ }^{\circledR}$ email: mgao@ustc.edu.cn; shyu@ustc.edu.cn
} 
O ver the past few years, market penetration by hydrogen fuel cell vehicles has begun owing to the tremendously advanced proton exchange membrane fuel cell (PEMFC) technologies ${ }^{1}$. Nevertheless, considerable market barriers still exist because current PEMFCs rely heavily on platinum (Pt)based catalysts that drive the sluggish cathode oxygen reduction reaction (ORR) at low $\mathrm{pHs}$, which raises poor cost competitiveness $^{2}$. Alternatively, hydroxide exchange membrane fuel cells (HEMFCs) give critical merits over PEMFCs, which permit the adoption of Pt group metal (PGM)-free catalysts to negotiate the formidable $\mathrm{ORR}^{3-5}$, leading to substantial cost reduction. Unfortunately, the anode hydrogen oxidation reaction (HOR) activity on PGM catalysts (e.g., Pt, Ir, and Pd) is about two to three orders of magnitude slower in alkali than in acidic electrolytes $^{6,7}$. This consequently causes higher PGM loadings at the anode that could largely offset the reduced cost from the use of PGM-free cathodes ${ }^{8}$. As a result, the development of durable PGM-free catalytic materials with high intrinsic HOR activity in alkali is important to the eventual success of HEMFC technology.

Recent advances in the design of alkaline HOR catalysts and related mechanistic understanding have primarily focused on PGMs and their alloys ${ }^{9-11}$. Numerous PGMs, such as Pt, palladium $(\mathrm{Pd})$, iridium (Ir), ruthenium $(\mathrm{Ru})$, and rhodium $(\mathrm{Rh}$,$) have$ been studied for HOR in alkaline electrolytes ${ }^{10,12}$, among which $\mathrm{Pt}$ and Ir are particularly active and stable. Moreover, alloying PGMs with other metals can enable performance enhancements resulting from the modified surface structures; typical examples include $\mathrm{PtNi}^{13}, \mathrm{PtRu}^{14}$, Pt-coated $\mathrm{Cu}^{15}$, body-centered cubic $\mathrm{PdCu}^{9}$, and others ${ }^{16-20}$. In the quest to understand why the HOR reactivity in alkaline media is significantly slower than that in acid on PGMs, there has been extensive debate over whether such sluggish HOR kinetics in alkali is determined by hydrogen binding energy (HBE) or $\mathrm{OH}$ binding energy (OHBE)/ oxophilicity $8,10,11,13,21-27$. The lack of a conclusive mechanistic relevance has somewhat hampered success in designing betterperforming HOR catalysts from PGMs. With regard to costeffective HEMFC anode, replacement of the PGMs with PGMfree catalysts-for example, nickel $(\mathrm{Ni})^{28}, \mathrm{Ni}_{3} \mathrm{~N}^{29}, \mathrm{Ni} / \mathrm{CeO}_{2}{ }^{30}, \mathrm{Ni}$ / $\mathrm{NiO} / \mathrm{C}^{31}, \mathrm{NiMo} / \mathrm{C}^{32}, \mathrm{CoNiMo}^{33}, \mathrm{Ni} / \mathrm{N}$-doped carbon nanotubes ${ }^{34}$, and $\mathrm{Cr}$-decorated $\mathrm{Ni}^{35}$-has been intensively proposed. However, the HOR activity and durability of these Ni-based catalysts are ordinary. To our best knowledge, although numerous efforts have been devoted to developing PGM-free catalysts for alkaline HOR since $1960 \mathrm{~s}^{36}$, no catalyst with activity superior to commercial $\mathrm{Pt} / \mathrm{C}$ has been reported, which severely limits their practical adoption in HEMFCs.

Herein, we report an important development in totally PGMfree HEMFC anode by using bimetallic $\mathrm{MoNi}_{4}$ alloy as a catalyst, which enables the HOR catalysis in alkaline electrolytes highly efficient. The nanostructured $\mathrm{MoNi}_{4}$ catalyst yields a geometric exchange current density of $3.41 \mathrm{~mA} \mathrm{~cm}^{-2}$ towards the HOR, which is 1.4 times higher than that of commercial $\mathrm{Pt} / \mathrm{C}$ catalyst and compares superior to previously reported PGM-free catalysts measured in alkali. At $50 \mathrm{mV}$, a geometric kinetic current density of $33.8 \mathrm{~mA} \mathrm{~cm}^{-2}$ is obtained for $\mathrm{MoNi}_{4}$ catalyst, which represents 105- and 2.8-fold increase as compared to the freshly synthesized $\mathrm{Ni}$ and commercial $\mathrm{Pt} / \mathrm{C}$ catalyst, respectively. This alloy catalyst also shows impressive tolerance against surface poisoning by impurity carbon monoxide (CO) in hydrogen fuel. We find that the HOR activity does not degrade obviously after $20 \mathrm{~h}$ of operation. The high reactivity is obtained by the optimized $\mathrm{Ni}$-molybdenum (Mo) alloy nanostructure and surface that offer synergistic optimization for the adsorption of hydrogen on $\mathrm{Ni}$ and hydroxyl on adjacent Mo (tungsten (W)). Similarly designed $\mathrm{WNi}_{4}$ alloy also demonstrates marked HOR activity in alkaline environments. Our results thus suggest a promising alloy design strategy for producing active and durable HOR catalysts for lowcost HEMFC anodes.

\section{Results}

Synthesis and characterization of $\mathrm{Ni}-\mathrm{Mo} / \mathrm{W}$. We designed HOR catalysts on the basis of $\mathrm{Ni}$ and $\mathrm{Mo}(\mathrm{W})$ because they were thought to be essential elements of hydrogenase enzymes ${ }^{37,38}$ and because Ni-based compounds have been observed to mediate the HOR catalysis in alkali with mild rates ${ }^{31,34}$. We first synthesized the sheet-like Mo (W)-doped $\mathrm{Ni}(\mathrm{OH})_{2}$ precursors through microwave heating of $\mathrm{Ni}\left(\mathrm{NO}_{3}\right)_{2} \cdot 6 \mathrm{H}_{2} \mathrm{O}$ and $\left(\mathrm{NH}_{4}\right)_{6} \mathrm{Mo}_{7} \mathrm{O}_{24} \cdot 4 \mathrm{H}_{2} \mathrm{O}$ (or $\left(\mathrm{NH}_{4}\right)_{10} \mathrm{~W}_{12} \mathrm{O}_{41} \cdot x \mathrm{H}_{2} \mathrm{O}$ ) in a $\mathrm{NH}_{3} \cdot \mathrm{H}_{2} \mathrm{O} /$ ethylene glycol/ $/ \mathrm{H}_{2} \mathrm{O}$ mixture at $200{ }^{\circ} \mathrm{C}$ (Fig. 1a and Supplementary Figs. 1 and 2). The resultant green powders were then annealed in hydrogen/argon $\left(\mathrm{H}_{2} / \mathrm{Ar}: 5 / 95\right)$ atmosphere at $400{ }^{\circ} \mathrm{C}$ to produce Mo-Ni alloy (or $500{ }^{\circ} \mathrm{C}$ for $\mathrm{W}-\mathrm{Ni}$ alloy; Fig. 1a). Our microwave reactor equipped with an automatic arm enables us to gain multigram-scale Mo (W) $-\mathrm{Ni}$ alloys in one batch (insets in Fig. 1b, e), implying a potentially large-scale use. Both two obtained alloys reveal similar morphologies when imaged by scanning electron microscopy (SEM) (Fig. 1b, e). More slit-like pores that were generated by aggregation of nanosheets during annealing process are seen for Mo-Ni alloy (Fig. 1b). Aberration-corrected high-angle annular dark-field scanning transmission electron microscopy (HAADFSTEM) of Mo-Ni alloy shows interconnected nanosheets with porous surfaces (Fig. 1c and Supplementary Fig. 3), whereas the $\mathrm{W}-\mathrm{Ni}$ alloy was formed as an aggregation of overlapping nanoparticles (Fig. 1f and Supplementary Fig. 4). The morphological features yield Brunauer-Emmett-Teller (BET) surface areas of 63.3 and $33.9 \mathrm{~m}^{2} \mathrm{~g}^{-1}$ for Mo-Ni and $\mathrm{W}-\mathrm{Ni}$ alloys (Supplementary Fig. 5), respectively. Atomic-resolution HAADF-STEM images with corresponding fast FT analyses demonstrate the formation of tetragonal $\mathrm{MoNi}_{4}$ and $\mathrm{WNi}_{4}$ crystalline phases (Fig. 1d, g, insets). Abundant atomic steps on the surface of $\mathrm{MoNi}_{4}$ and $\mathrm{WNi}_{4}$ alloys can be observed (see white arrows in Fig. 1d, g), probably induced by the high-temperature annealing treatments. X-ray diffraction (XRD) studies further confirm the successful transformation of $\mathrm{Mo}(\mathrm{W})$-doped $\mathrm{Ni}(\mathrm{OH})_{2}$ precursors (Supplementary Fig. 1) into fully alloyed tetragonal $\mathrm{MoNi}_{4}$ (JCPDS 65-5480) and $\mathrm{WNi}_{4}$ (JCPDS 65-2673) phases (Fig. 1h; corresponding crystal structures are shown as insets). It is noted that the diffraction peaks of $\mathrm{MoNi}_{4}$ and $\mathrm{WNi}_{4}$ differ from those of pure $\mathrm{Ni}$ synthesized by the same route (Fig. 1h and Supplementary Fig. 6), suggesting the alloy-induced structural change that might tune the catalytic functions. Energy-dispersive X-ray (EDX) spectrum elemental mapping in Fig. 1i presents a uniform spatial distribution of $\mathrm{Mo}(\mathrm{W})$ and $\mathrm{Ni}$ in $\mathrm{Mo}(\mathrm{W}) \mathrm{Ni}_{4}$ products, and the overall $\mathrm{Mo}(\mathrm{W})$ to $\mathrm{Ni}$ ratio was determined to be $1: 4$ on the basis of EDX and inductively coupled plasma atomic emission spectroscopy (ICP-AES) measurements (Supplementary Fig. 7 and Supplementary Table 1).

The X-ray absorption spectroscopy is used to probe the impact of alloying $\mathrm{Mo}(\mathrm{W})$ on the $\mathrm{Ni}$ chemical environment. Figure 2a presents the $\mathrm{X}$-ray absorption near-edge structure (XANES) spectra of $\mathrm{MoNi}_{4}$ and $\mathrm{WNi}_{4}$ at $\mathrm{Ni} \mathrm{K}$-edge, which are similar to those of the freshly synthesized $\mathrm{Ni}$ and $\mathrm{Ni}$ foil references, but greatly differ from that of $\mathrm{NiO}$ reference, indicating the metallic nature of the alloyed products. The radial structure function around Ni was determined by Fourier transform (FT) of extended $\mathrm{X}$-ray absorption fine-structure (EXAFS) spectra (Fig. 2b and Supplementary Fig. 8). We associated the major peak at $\sim 2.2 \AA$ with $\mathrm{Ni}-\mathrm{Mo}(\mathrm{Ni})$ and $\mathrm{Ni}-\mathrm{W}(\mathrm{Ni})$ bonds in $\mathrm{MoNi}_{4}$ and $\mathrm{WNi}_{4}$ alloys $^{39,40}$. No $\mathrm{Ni}-\mathrm{O}$ and $\mathrm{Ni}-\mathrm{Ni}$ bonds belonging to $\mathrm{NiO}$ reference have been observed. The decrease in peak intensity as compared to $\mathrm{Ni}-\mathrm{Ni}$ bonds in freshly synthesized $\mathrm{Ni}$ and $\mathrm{Ni}$ foil 
a
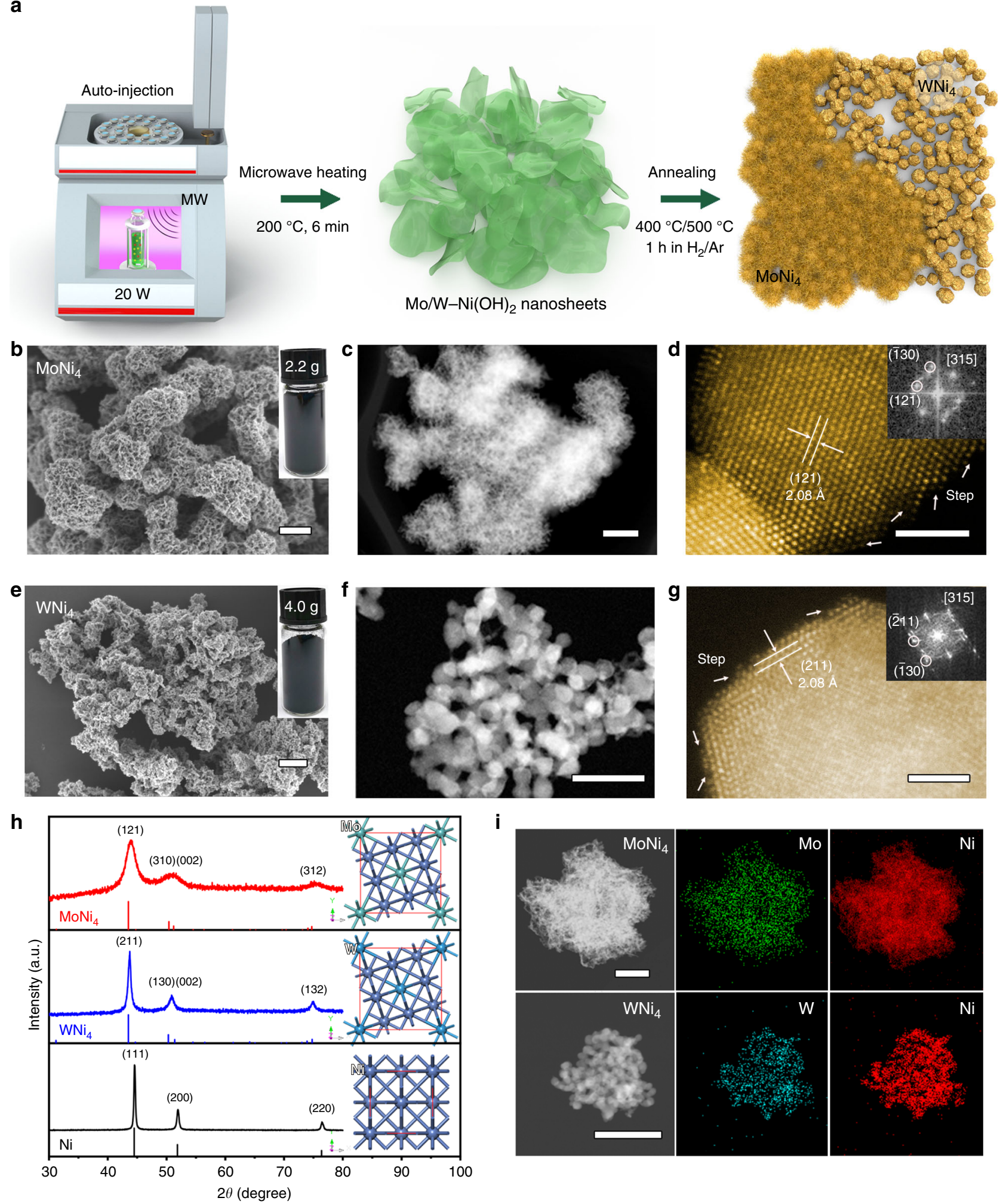

Fig. 1 Synthesis and physical characterization of $\mathbf{M o N i}_{\mathbf{4}}$ and $\mathbf{W N i}$ alloys. a Schematic illustration of the synthesis of $\mathrm{MoNi}_{4}$ and $\mathrm{WNi} \mathrm{N}_{4}$ alloys. $\mathbf{b}$, e $\mathrm{SEM}$ images of $\mathrm{MoNi}_{4}$ and $\mathrm{WNi}_{4}$ alloys, respectively. Scale bars, $200 \mathrm{~nm}$. Insets in $\mathbf{b}$, e are photographs of $\mathrm{MoNi}_{4}(2.2 \mathrm{~g})$ and $\mathrm{WNi}_{4}(4.0 \mathrm{~g})$ alloys synthesized in one batch. c, f STEM images of $\mathrm{MoNi}_{4}$ and $\mathrm{WNi}_{4}$ alloys, respectively. Scale bars, $200 \mathrm{~nm} \mathbf{c}$ and $50 \mathrm{~nm} \mathbf{f}$. d, $\mathbf{g}$ Atomic-resolution HAADF-STEM images of typical $\mathrm{MoNi}_{4}$ and $\mathrm{WNi}_{4}$ particles, respectively. Scale bars, $2 \mathrm{~nm}$. Insets in $\mathbf{d}, \mathbf{g}$ show corresponding FFT patterns. The white arrows denote atomic steps. h XRD patterns of $\mathrm{MoNi}_{4}, \mathrm{WNi}_{4}$, and freshly synthesized $\mathrm{Ni}$. Insets give corresponding crystal structures. i STEM-EDX elemental mappings of MoNi ${ }_{4}$ and $\mathrm{WNi}_{4}$ alloys. Scale bars, $500 \mathrm{~nm}$ (up) and $100 \mathrm{~nm}$ (down). 

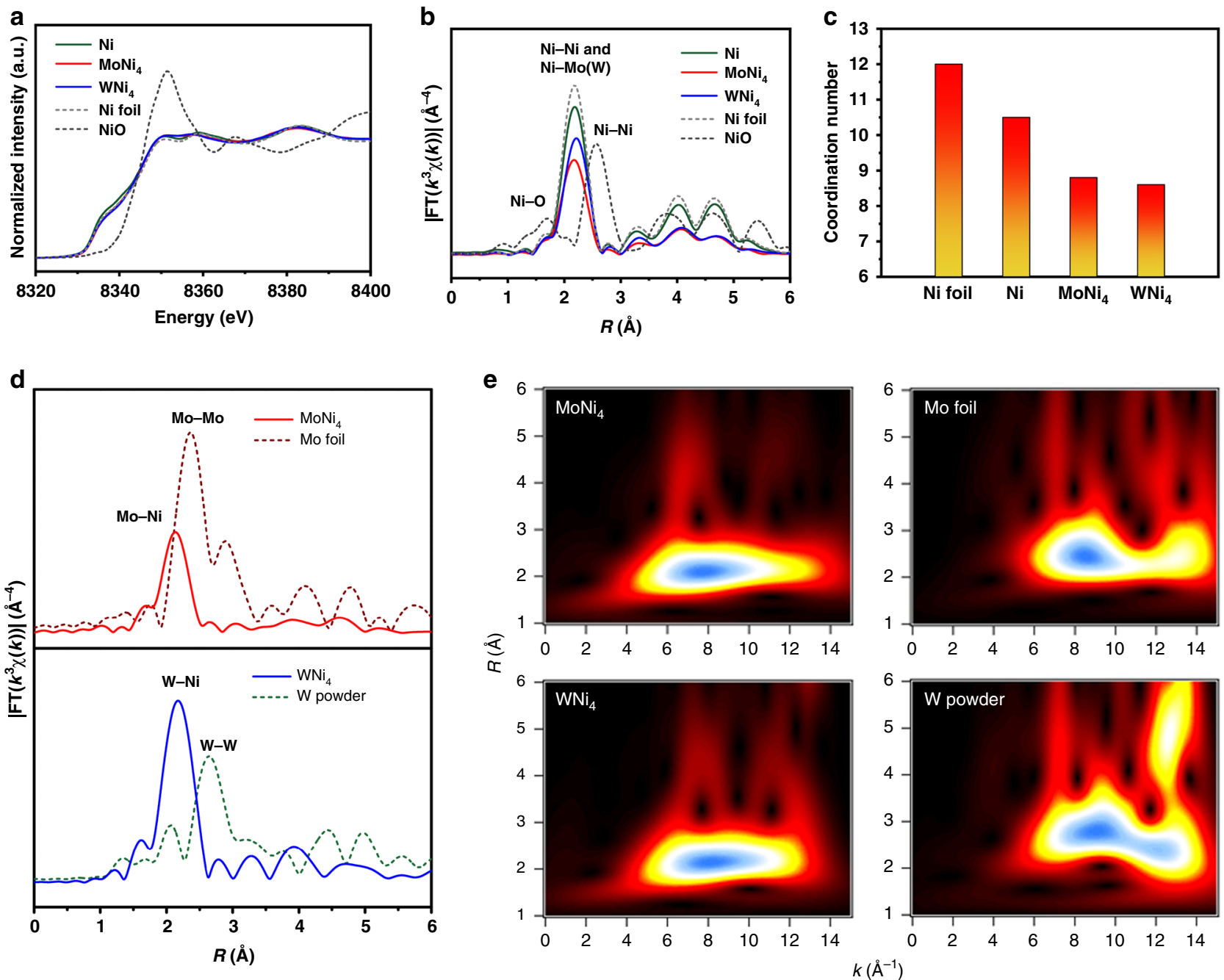

Fig. 2 Structural analyses of $\mathbf{M o N i}_{\mathbf{4}}$ and $\mathbf{W N i}$ alloys. $\mathbf{a}$, $\mathbf{b}$ Ni K-edge XANES spectra and corresponding Fourier transforms of $k^{3}$-weighted EXAFS spectra for $\mathrm{Mo}(\mathrm{W}) \mathrm{Ni}_{4}$ alloys, freshly synthesized $\mathrm{Ni}$, Ni foil, and $\mathrm{NiO}$ reference. $\mathbf{c}$ The average coordination numbers (CN) in the first coordination shell of $\mathrm{Ni}$ atoms for $\mathrm{MoNi}_{4}, \mathrm{WNi}_{4}$, and freshly synthesized Ni by EXAFS spectra curve fitting. The CN of bulk Ni (Ni foil) is 12. $\mathbf{d}$ Fourier transforms of $k^{3}$-weighted EXAFS spectra of Mo K-edge (up) and W $\mathrm{L}_{3}$-edge (down), respectively. e Corresponding wavelet transforms of $k^{3}$-weighted EXAFS spectra of Mo K-edge (up) and $W L_{3}$-edge (down), respectively.

indicates the damped coordination structure of $\mathrm{Ni}$. In addition, the Ni K-edge EXAFS fittings show that the first-shell Ni-Mo(W) coordination numbers (CNs) decrease from $\mathrm{Ni}(\sim 10.5)$ to $\mathrm{MoNi}_{4}$ $(\sim 8.8)$ and $\mathrm{WNi}_{4}(\sim 8.6)$, respectively. (Fig. 2c, Supplementary Fig. 9, and Supplementary Table 2). The lower CN could be attributed to the rich surface steps on our alloyed catalysts (Fig. 1d, g), which may increase the active sites that modulate the adsorption capability. The FT curves at Mo $\mathrm{K}$ and $\mathrm{W} \mathrm{L}_{3}$ edges in Fig. 2d show predominant peaks at $\sim 2.2 \AA$, corresponding to Mo-Ni and $\mathrm{W}-\mathrm{Ni}$ bonds (Supplementary Figs. 10 and 11), respectively. The results from EXAFS wavelet transform (Fig. 2e) -a powerful technique that can discriminate the backscattering atoms $s^{41}$-exhibit only one intensity maximum at $\sim 8.0 \AA^{-1}$ in $k$ space that corresponds to Mo-Ni and $\mathrm{W}-\mathrm{Ni}$ bonds in $\mathrm{MoNi}_{4}$ and $\mathrm{WNi}_{4}$ alloys. By contrast, wavelet transform analysis of Mo foil and $\mathrm{W}$ powder references give higher intensity maximum (Fig. 2e), suggesting that $\mathrm{Mo} / \mathrm{W}$ atoms are forming structures in which their first coordination shell is formed only by $\mathrm{Ni}$ atoms and no local Mo and $\mathrm{W}$ metals generate in the prepared alloys, in agreement with the results in Fig. 2d. In addition, the X-ray photoelectron spectroscopy (XPS) analyses indicate a superior surface passivation resistance of our alloyed catalysts as compared to single Ni (Supplementary Fig. 12). Together, we conclude that alloying $\mathrm{Ni}$ with $\mathrm{Mo}(\mathrm{W})$ cerates clear compositional and structural modulations, which we expect to benefit the HOR catalysis in alkaline electrolytes.

Electrocatalytic HOR in alkaline electrolytes. We now examine the electrocatalytic activity of the $\mathrm{MoNi}_{4}$ and $\mathrm{WNi}_{4}$ catalysts toward $\mathrm{HOR}$ in $\mathrm{H}_{2}$-saturated $0.1 \mathrm{M} \mathrm{KOH}$ electrolyte in a threeelectrode setup; with reference measurements of freshly synthesized $\mathrm{Ni}$ as well as commercial Pt/C (20 wt\% Pt on Vulcan XC72R carbon) for comparison (see "Methods"). A very slow sweep rate of $0.5 \mathrm{mV} \mathrm{s}^{-1}$ was selected to minimize the capacitance contribution and to guarantee a steady-state measurement (Supplementary Fig. 13). The optimal catalyst loading on inert glassy carbon rotating-disk electrode (RDE) was experimentally determined to be $0.5 \mathrm{mg} \mathrm{cm}^{-2}$ (Supplementary Fig. 14). We note that the electrochemical data reported here were $i R$-corrected $(i$, current; $R$, resistance) for the uncompensated Ohmic drop (Supplementary Fig. 15).

Polarization curves for the HOR on studied catalysts are given in Fig. 3a, which show that $\mathrm{MoNi}_{4}$ and $\mathrm{WNi}_{4}$ catalysts possess an 


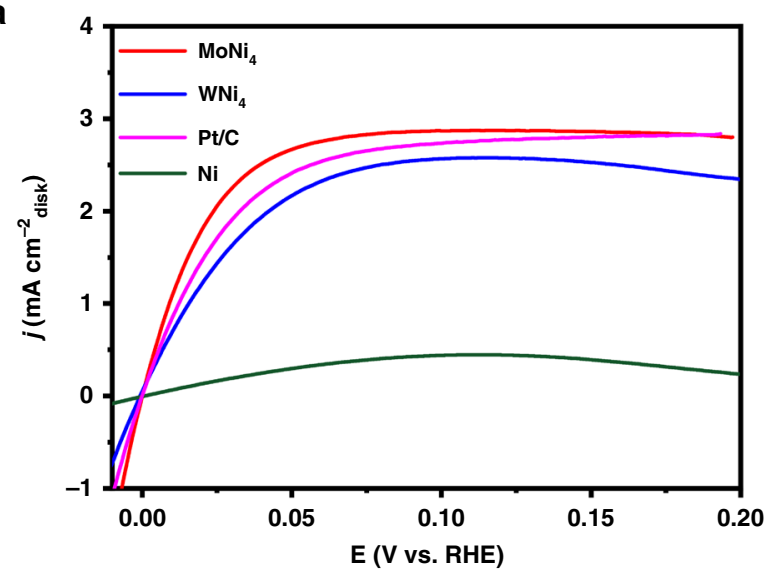

C
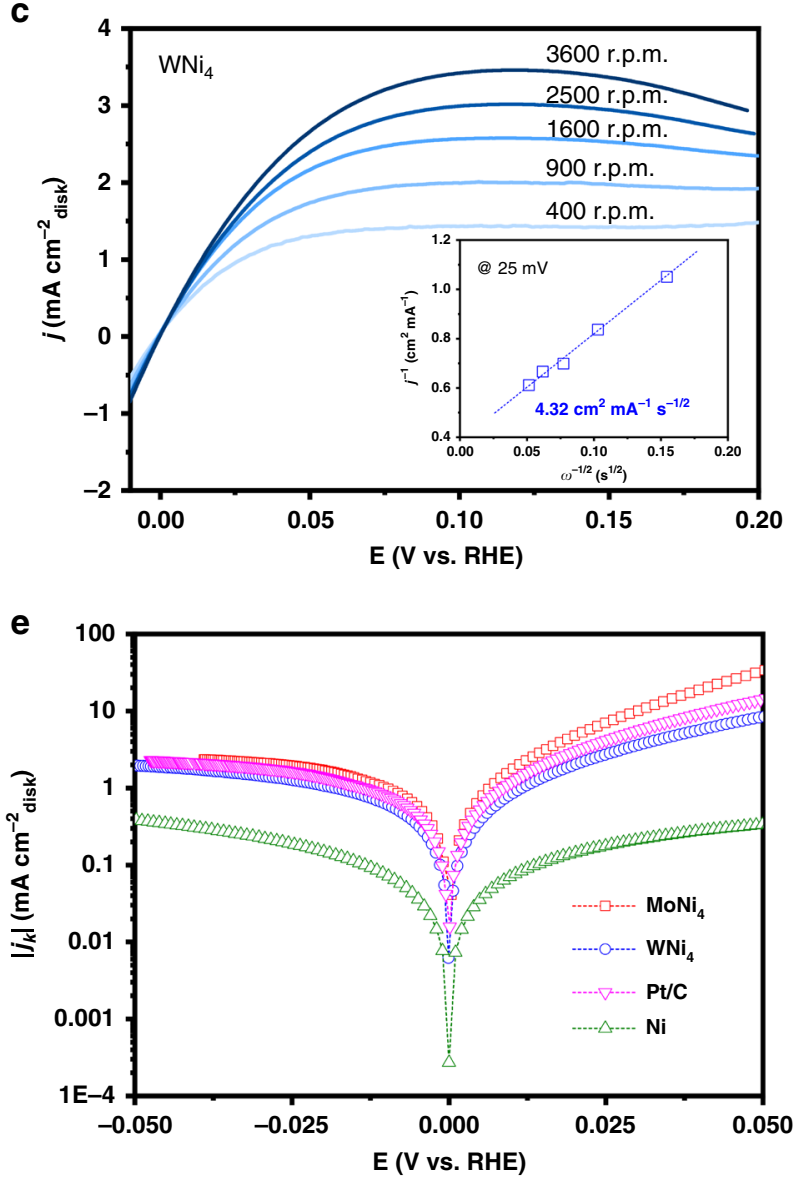
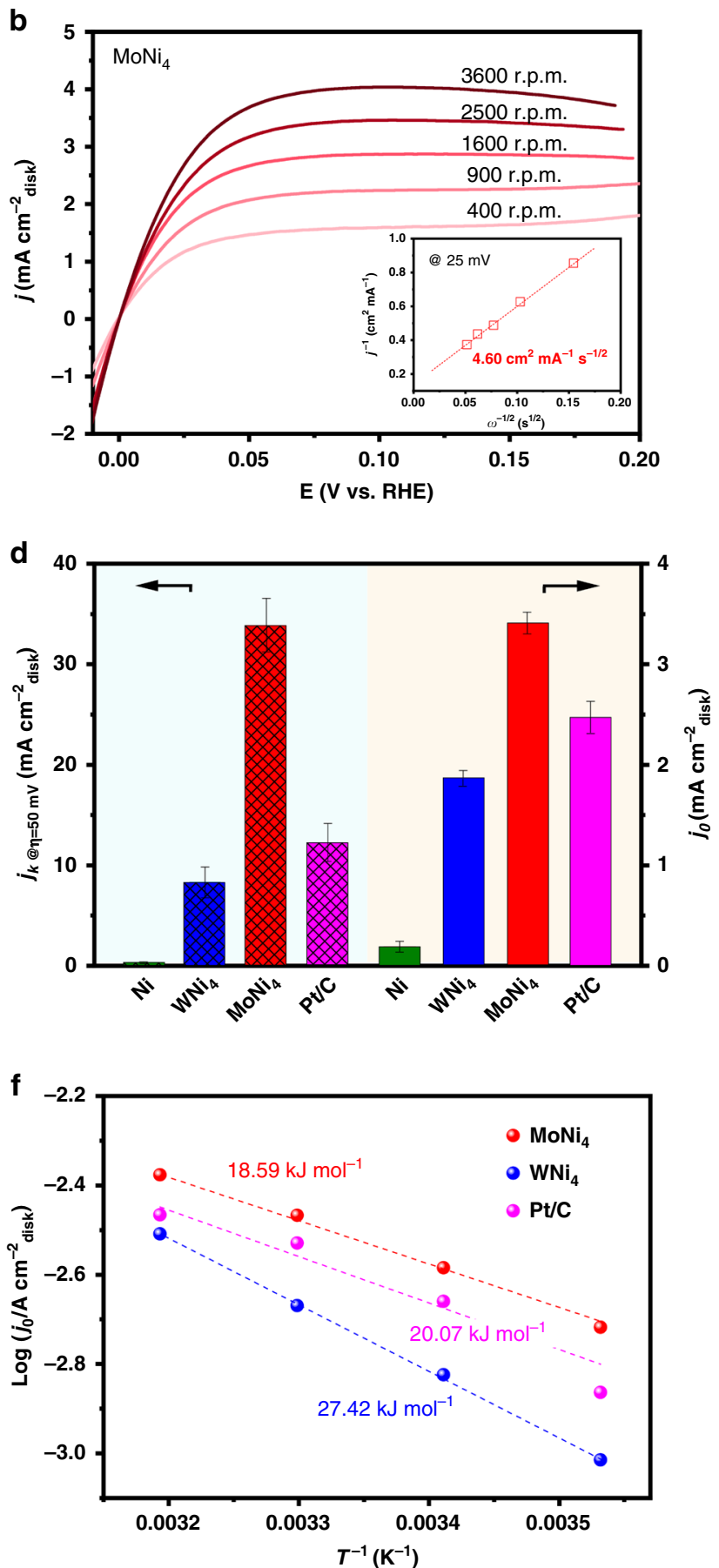

Fig. 3 Electrocatalytic HOR performances. a Polarization curves for the HOR on $\mathrm{MoNi}_{4}, \mathrm{WNi}_{4}$, freshly synthesized $\mathrm{Ni}$, and commercial Pt/C catalyst measured in $\mathrm{H}_{2}$-saturated $0.1 \mathrm{M} \mathrm{KOH}$. Sweep rate: $0.5 \mathrm{mV} \mathrm{s}^{-1}$. Rotation speed: 1600 r.p.m. b, c HOR polarization curves for $\mathrm{MoNi}_{4}$ and $\mathrm{WNi}_{4}$ alloys at various rotation speeds, respectively. Sweep rate: $0.5 \mathrm{mV} \mathrm{s}^{-1}$. Insets in $\mathbf{b}, \mathbf{c}$ show corresponding Koutecky-Levich plots at an overpotential of $25 \mathrm{mV}$. d Comparison of kinetic current density $\left(j_{k}\right)$ at $50 \mathrm{mV}$ (patterned) and apparent exchange current density ( $j_{0}$; unpatterned) of different studied catalysts. The error bars (standard deviations) in $\mathbf{d}$ are calculated based on three independent test results. e HOR/HER Tafel plots of the kinetic current density on $\mathrm{MoNi}_{4}, \mathrm{WNi}_{4}, \mathrm{Ni}$, and $\mathrm{Pt} / \mathrm{C}$ in $\mathrm{H}_{2}$-saturated $0.1 \mathrm{M} \mathrm{KOH}$. f Arrhenius plots of the HOR/HER exchange current densities on $\mathrm{MoNi}_{4}, \mathrm{WNi}_{4}$, and Pt/C catalysts in $0.1 \mathrm{M} \mathrm{KOH}$.

onset potential for yielding HOR current as low as $0 \mathrm{~V}$ versus the reversible hydrogen electrode (RHE), indicating their remarkable energetics for HOR in alkali. By contrast, the freshly synthesized Ni catalyst affects only negligible HOR activity. The two PGMfree HOR alloy catalysts can reach the diffusion-limiting current in the potential region $>0.05 \mathrm{~V}$, while a mixed kinetic-diffusion control region happens between 0 to $0.05 \mathrm{~V}$. Figure $3 \mathrm{a}$ also reveals that the $\mathrm{MoNi}_{4}$ catalyst even outperforms the state-of-the-art Pt/ $\mathrm{C}$ catalyst from the kinetic to the diffusion-limiting regions. The half-wave potential for $\mathrm{MoNi}_{4}$ catalyst at 1600 r.p.m. is mere 14 $\mathrm{mV}$, which is $\sim 5 \mathrm{mV}$ lower than that of the $\mathrm{Pt} / \mathrm{C}$ catalyst, further evidencing excellent $\mathrm{HOR}$ activity of the $\mathrm{MoNi}_{4}$ catalyst.

We then studied the HOR polarization curves on our $\mathrm{MoNi}_{4}$ and $\mathrm{WNi}_{4}$ catalysts as a function of the rotation rate, where the 
plateau current density grows with increasing rotation rate due to the promoted mass transport (Fig. 3b, c). The Koutecky-Levich plots constructed at $25 \mathrm{mV}$ show a linear relationship between the inverse of overall current density and the square root of the rotation rate, which yield calculated slopes of $4.60 \mathrm{~cm}^{2} \mathrm{~mA}^{-1} \mathrm{~s}^{-1 /}$ 2 for $\mathrm{MoNi}_{4}$ (inset in Fig. 3b) and $4.32 \mathrm{~cm}^{2} \mathrm{~mA}^{-1} \mathrm{~s}^{-1 / 2}$ for $\mathrm{WNi}_{4}$ (inset in Fig. $3 \mathrm{c}$ ), reasonably matching with the theoretical value of $4.87 \mathrm{~cm}^{2} \mathrm{~mA}^{-1} \mathrm{~s}^{-1 / 2}$ for the two-electron HOR process ${ }^{34}$. We further used Koutecky-Levich equation to calculate the kinetic current density $\left(j_{\mathrm{k}}\right)$. At $50 \mathrm{mV}$, a geometric $j_{\mathrm{k}}$ of $33.8 \mathrm{~mA} \mathrm{~cm}^{-2}$ was obtained for $\mathrm{MoNi}_{4}$ catalyst, which represents 105- and 2.8fold increase compared with those of freshly synthesized $\mathrm{Ni}$ and commercial Pt/C catalysts (Fig. 3d).

Next, we extracted the exchange current density $\left(j_{0}\right)$ on studied catalysts from linear fitting of micropolarization regions $(-5$ to 5 $\mathrm{mV}$; Supplementary Fig. 16). The $\mathrm{MoNi}_{4}$ catalyst shows a geometric $j_{0}$ of $3.41 \mathrm{~mA} \mathrm{~cm}^{-2}$, far higher than $0.19 \mathrm{~mA} \mathrm{~cm}^{-2}$ for the freshly synthesized $\mathrm{Ni}$ and $2.47 \mathrm{~mA} \mathrm{~cm}^{-2}$ for the $\mathrm{Pt} / \mathrm{C}$ catalyst (Fig. 3d and Supplementary Table 3). The geometric $j_{0}$ on $\mathrm{WNi}_{4}$ catalyst is $1.87 \mathrm{~mA} \mathrm{~cm}^{-2}$, which is slightly lower than that of $\mathrm{Pt} / \mathrm{C}$ catalyst. These values are in good agreement with the fitting results of Butler-Volmer equation in the Tafel regions (Fig. 3e; see "Methods" for details). Intrinsic HOR activities of studied catalysts were further compared by the electrochemical active surface area (ECSA)-normalized $j_{0}$ (for details see "Methods" and Supplementary Figs. 17 and 18). The $\mathrm{MoNi}_{4}$ and $\mathrm{WNi}_{4}$ catalysts deliver very high ECSA-normalized $j_{0}$ of 0.065 and $0.068 \mathrm{~mA} \mathrm{~cm}$ -2 , respectively, which, to the best of our knowledge, has not been achieved by any other PGM-free catalysts in alkaline electrolytes, including various Ni-based compounds synthesized by other methods (Supplementary Fig. 19 and Supplementary Table 4).

In addition, we probed the activation energy $\left(E_{\mathrm{a}}\right)$ of the HOR on studied catalysts via plotting geometric $j_{0}$ with the inverse of temperature (Fig. 3f). It has been found that a linear relationship between 283 and $313 \mathrm{~K}$ follows the Arrhenius behavior, from which $E_{\mathrm{a}}$ values of $18.59,27.42$, and $20.07 \mathrm{~kJ} \mathrm{~mol}^{-1}$ were obtained for the $\mathrm{MoNi}_{4}, \mathrm{WNi}_{4}$, and $\mathrm{Pt} / \mathrm{C}$ catalysts (Fig. $3 \mathrm{f}$ and Supplementary Figs. 20 and 21), respectively. We note that the $E_{\mathrm{a}}$ of $20.07 \mathrm{~kJ} \mathrm{~mol}^{-1}$ measured for $\mathrm{Pt} / \mathrm{C}$ catalyst matches reasonably with $23 \mathrm{~kJ} \mathrm{~mol}^{-1}$ for $\mathrm{Pt}(110)$ reported previously ${ }^{25}$. The considerably smaller $E_{\mathrm{a}}$ values achieved for $\mathrm{MoNi}_{4}$ catalyst suggest marked kinetics for HOR in alkaline environments, even outperforming the $\mathrm{Pt} / \mathrm{C}$ benchmark. Moreover, we conducted a series of control experiments and disclosed that the $\mathrm{Mo}(\mathrm{W})$ to $\mathrm{Ni}$ ratio and the annealing temperature are critical to the HOR activity (Supplementary Figs. 22 and 25). These experiments show that Mo-Ni and $\mathrm{W}-\mathrm{Ni}$ alloys with $\mathrm{Mo}(\mathrm{W})$ to Ni ratios of 1:4 obtained by annealing at 400 and $500{ }^{\circ} \mathrm{C}$, respectively, would lead to the best HOR performances. We further note that our $\mathrm{MoNi}_{4}$ sheets outperform conventional $\mathrm{MoNi}_{4}$ nanoparticles for HOR owing to the porous structure that offers rich active sites (Supplementary Fig. 26).

The results above demonstrate exceptional HOR catalysis in alkaline electrolytes on $\mathrm{MoNi}_{4}$ and $\mathrm{WNi}_{4}$ catalysts, from which the reactivity of $\mathrm{MoNi}_{4}$ even exceeds that of $\mathrm{Pt} / \mathrm{C}$ benchmark. Besides activity, another very important factor for future HEMFC anode applications is electrochemical and operating stabilities. We therefore conducted aggressive long-term stability measurements on the $\mathrm{MoNi}_{4}$ and $\mathrm{WNi}_{4}$ catalysts (Fig. 4). First, we performed accelerated stability tests by applying linear potential scans between 0.05 and $0.15 \mathrm{~V}$ at $100 \mathrm{mV} \mathrm{s}^{-1}$ in $\mathrm{H}_{2}$-saturated 0.1 $\mathrm{M} \mathrm{KOH}$ electrolytes at room temperature. At $50 \mathrm{mV}$ overpotential, the HOR current density for $\mathrm{MoNi}_{4}$ catalyst shows a small loss of $0.25 \mathrm{~mA} \mathrm{~cm}^{-2}$ after 2000 cycles (Fig. 4a), versus a loss of $0.41 \mathrm{~mA} \mathrm{~cm}^{-2}$ for $\mathrm{WNi}_{4}$ catalyst (Fig. $4 \mathrm{~b}$ ). Second, the studied catalysts were deposited onto carbon papers (catalyst loading: $2 \mathrm{mg} \mathrm{cm}^{-2}$ ) and assessed the operational stability by means of chronoamperometry $(j \sim \mathrm{t})$. Figure $4 \mathrm{c}$ shows that the current density at $60 \mathrm{mV}$ is stable without noticeable decay during a $20 \mathrm{~h}$ continuous test for $\mathrm{MoNi}_{4}$ catalyst, whereas no HOR current was generated in Ar-saturated $0.1 \mathrm{M} \mathrm{KOH}$ at the same overpotential (Supplementary Fig. 27). Multiple "postmortem" characterizations display that the morphology and structure of $\mathrm{MoNi}_{4}$ catalyst are well maintained (Supplementary Figs. 28-30). By contrast, $\mathrm{Pt} / \mathrm{C}$ catalyst undergoes a marked degradation, which retains a mere $57 \%$ of its original current density after $20 \mathrm{~h}$ operation. This large drop could be ascribed to the gradual agglomeration of Pt nanoparticles during the stability test (Supplementary Fig. 31). The $\mathrm{WNi}_{4}$ catalyst also shows degradation, but at a much slower manner in comparison to the Pt/C catalyst (Fig. 4c and Supplementary Figs. 28, 29, 32). These results thus suggest that our $\mathrm{MoNi}_{4}$ and $\mathrm{WNi}_{4}$ catalysts have stability much better than the commercial Pt/C catalyst.

CO-tolerance evaluation. In fuel cells, PGM catalysts (especially $\mathrm{Pt}$ ) at the anodes are readily poisoned by impurity gas such as $\mathrm{CO}$ that existed in hydrogen fuel. Such poisoning is caused by the preferential CO binding on $\mathrm{Pt}$, which consequently blocks the sites for hydrogen adsorption and dissociation. Unexpectedly, we observed that the $\mathrm{MoNi}_{4}$ catalyst shows exciting HOR activity even in the presence of 20,000 p.p.m. CO (Fig. 4d). At the same $\mathrm{CO}$ concentration, no $\mathrm{HOR}$ activity on the $\mathrm{Pt} / \mathrm{C}$ catalyst was detected, suggesting complete poisoning of the sites for $\mathrm{H}_{2}$ oxidation by CO binding (Fig. 4d). Our density functional theory (DFT) calculations exhibit a significant higher $\mathrm{CO}$ adsorption ability of $\mathrm{Pt}$ as compared to the $\mathrm{MoNi}_{4}$ alloy (Supplementary Fig. 33), leading to the surface of Pt covered by CO and thus deactivation. Moreover, the preferable $\mathrm{OH}$ adsorption on $\mathrm{MoNi}_{4}$ surface assists in the oxidation of $\mathrm{CO}$ adsorbed, which also explains its notable $\mathrm{CO}$-tolerance property. The high $\mathrm{CO}$ tolerance of our $\mathrm{MoNi}_{4}$ alloy catalyst could further affect the quest for designing advanced fuel cell anodes based on PGM-free materials.

HOR enhancement mechanism. Although $\mathrm{Ni}$ and $\mathrm{Ni}$-based materials have been extensively studied as PGM-free HOR catalysts in alkaline electrolytes, almost all previous Ni-based HOR catalysts demonstrate a relatively low level of activity and their long-term stability is also problematic. Here, the superb HOR catalytic capability observed on our readily made $\mathrm{MoNi}_{4}$ and $\mathrm{WNi}_{4}$ alloys prompted us to investigate the intrinsic mechanism of the high performances, thus offering a guide for the design of more advanced HOR catalysts.

We studied the electronic structures of $\mathrm{MoNi}_{4}, \mathrm{WNi}_{4}$, and freshly synthesized $\mathrm{Ni}$ by using ultraviolet photoelectron spectroscopy). From the valence band spectra, we found that all these catalysts have electronic bands across the Fermi level ( $E_{\mathrm{F}}$; Fig. 5a). The peaks located between 0 and $2 \mathrm{eV}$ could be ascribed to the metal $d$-band ${ }^{42,43}$, which reaches the maximum at $0.28,0.80$, and $1.09 \mathrm{eV}$ for freshly synthesized $\mathrm{Ni}, \mathrm{MoNi}_{4}$, and $\mathrm{WNi}_{4}$, respectively. The metal $d$-band maximum with respect to the $E_{\mathrm{F}}$ in our $\mathrm{MoNi}_{4}$ and $\mathrm{WNi}_{4}$ alloys shifted far away relative to the $\mathrm{Ni}$ reference. According to the $d$-band theory, these results suggest that the filling of metal-H antibonding states above $E_{\mathrm{F}}$ is improved for $\mathrm{MoNi}_{4}$ and $\mathrm{WNi}_{4}$ catalysts, affording them a weaker adsorption energy as compared to $\mathrm{Ni}^{44}$. Despite the HOR mechanism on PGMs in alkaline environments is still under debate, previous studies have proposed that the low HOR activity on $\mathrm{Ni}$ catalyst was caused by the too high $\mathrm{HBE}^{34}$. Thus, we partially attribute the notable $\mathrm{HOR}$ reactivity observed on $\mathrm{MoNi}_{4}$ and $\mathrm{WNi}_{4}$ catalysts to the appropriately weakened HBEs. 

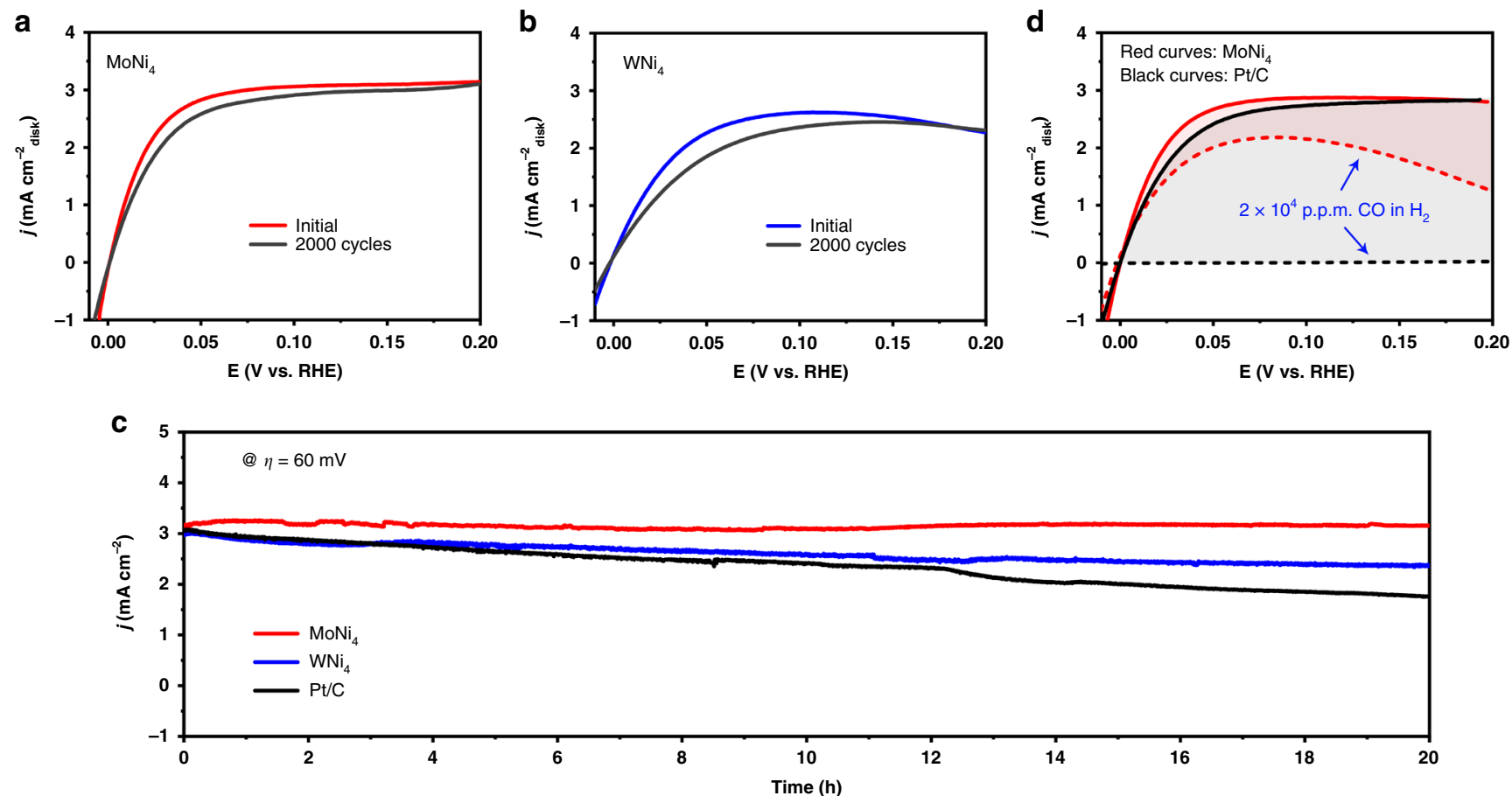

Fig. 4 Performance stability and CO resistance. a, b HOR polarization curves for $\mathrm{MoNi}_{4}$ and $\mathrm{WNi}_{4}$ alloys in $\mathrm{H}_{2}$-saturated $0.1 \mathrm{M} \mathrm{KOH}$ before and after 2000 cycles, respectively. c Chronoamperometry $(j-t)$ responses recorded on $\mathrm{MoNi}_{4}, \mathrm{WNi}_{4}$, and Pt/C catalysts at a $60 \mathrm{mV}$ overpotential in $\mathrm{H}_{2}$-saturated $0.1 \mathrm{M} \mathrm{KOH}$. $\mathbf{d} \mathrm{HOR}$ polarization curves for $\mathrm{MoNi}_{4}$ and $\mathrm{Pt} / \mathrm{C}$ alloys in $\mathrm{H}_{2}$-saturated $0.1 \mathrm{M} \mathrm{KOH}$ with (dashed lines) and without (solid lines) the presence of 20,000 p.p.m. CO.

We note that OHBE, or both $\mathrm{HBE}$ and OHBE, are also thought to be the activity descriptor for HOR catalysis, which have recently been theoretically predicted and experimentally explored ${ }^{9,27}$, such as the study on $\mathrm{PdCu}$ nanocatalyst for alkaline $\mathrm{HOR}^{9}$. Considering that $\mathrm{CO}$ can adsorb specifically on many metal surfaces $10,45,46$, we thus performed CO-stripping experiments to monitor the $\mathrm{OH}$ binding on our catalyst surface because $\mathrm{OH}_{\mathrm{ad}}$ facilitates the removal of $\mathrm{CO}_{\mathrm{ad}}{ }^{21}$. Results of our COstripping experiments shown in Fig. 5b reveal that CO-stripping peak on $\mathrm{Pt} / \mathrm{C}$ catalyst locates at $0.69 \mathrm{~V}$, consistent with the previous reports ${ }^{23}$. Figure $5 \mathrm{~b}$ further shows lower CO-stripping peaks at 0.52 and $0.49 \mathrm{~V}$ for $\mathrm{MoNi}_{4}$ and $\mathrm{WNi}_{4}$ catalysts, whereas the freshly synthesized Ni exhibits negligible CO-stripping peak. Some prior works have ascribed the sluggish HOR kinetics on $\mathrm{Pt}$ to its weak $\mathrm{OH}_{\mathrm{ad}}$ binding in alkali ${ }^{8,23,27}$. Our CO-stripping results here suggest that the enhanced OHBE on $\mathrm{MoNi}_{4}$ and $\mathrm{WNi}_{4}$ could also be responsible for their high HOR energetics.

To better understand the mechanism underlying the notable HOR performance, DFT calculations were further performed. We created and optimized catalyst models of $\mathrm{MoNi}_{4}(211)$, $\mathrm{WNi}_{4}(211), \mathrm{Ni}(111)$, and $\mathrm{Pt}(111)$ to represent the catalytic surfaces (see "Methods"; Supplementary Figs. 34-36). The DFT results show that the $\mathrm{HBE}$ of $\mathrm{Ni}(111)$ is too strong, while $\mathrm{MoNi}_{4}(211)$ gives a very similar $\mathrm{HBE}$ with $\mathrm{Pt}(111)$ model (Fig. $5 \mathrm{c}-\mathrm{f}$ ). When comparing the OHBE of $\mathrm{MoNi}_{4}(211)$ with that of $\mathrm{Pt}(111)$, we observed a greatly promoted hydroxyl adsorption, which can explain the superior HOR reactivity of $\mathrm{MoNi}_{4}$ catalyst (Fig. 5c-f and Supplementary Table 3). Our computational results suggest that alloying $\mathrm{Ni}$ with $\mathrm{Mo}(\mathrm{W})$ not only weakens the HBE on Ni sites but also permits an enhanced $\mathrm{OHBE}$ on the $\mathrm{Mo}(\mathrm{W})$ sites, which substantially promote the key Volmer step (Supplementary Figs. 37-39), leading to the HOR enhancements. We also computed the HBE and OHBE of other catalysts, such as $\mathrm{Mo}, \mathrm{W}, \mathrm{CoNi}_{4}$, and $\mathrm{FeNi}_{4}$, for comparison (Fig. 5c and Supplementary Figs. 36 and 40), and more calculation information are shown in Supplementary Figs. 38, 39 , and 41 . The simulations reveal that although these materials have stronger OHBE than $\mathrm{Pt}(111)$, their HBEs are unfortunately too strong (Fig. 5c), giving rise to the poor HOR activity (Supplementary Figs. 42-45).

Taken together, our UPS and CO-stripping measurements, in conjunction with DFT calculations, have proposed that a synergistic interplay between HBE and OHBE likely determines the HOR rate in alkaline electrolytes; and the striking HOR reactivity observed on $\mathrm{MoNi}_{4}$ and $\mathrm{WNi}_{4}$ alloys could be interpreted as the optimum adsorption of hydrogen on $\mathrm{Ni}$ and hydroxyl on $\mathrm{Mo}(\mathrm{W})$, thus boosting the rate-limiting Volmer reaction in alkaline HOR catalysis (Fig. $5 \mathrm{~d}-\mathrm{f}$ and Supplementary Fig. 46).

\section{Discussion}

In conclusion, ultrahigh $\mathrm{HOR}$ activity in the alkaline electrolyte has been achieved on PGM-free bimetallic $\mathrm{MoNi}_{4}$ and $\mathrm{WNi}_{4}$, from which the $\mathrm{MoNi}_{4}$ exhibits exceptional apparent exchange current density that even outperforms the commercial $\mathrm{Pt} / \mathrm{C}$ catalyst. We explain such high HOR rates of our catalysts by the optimized adsorption of both hydrogen and hydroxyl species owing to a synergistic effect between Ni and Mo (W). The catalysts do not show obvious deactivation over a 20 -h testing period and demonstrate a good CO-tolerant property. We anticipate that further improvement in activity would be attainable by alloying other metallic elements into a single nanocatalyst. Our results reinforce the importance of alloy design concept for obtaining high-performance PGM-free HOR catalysts for future HEMFC anodes.

\section{Methods}

Synthesis of $\mathbf{M o N i}_{4}$ and $\mathbf{W N i}$ alloys. All chemicals were used as received without further purification. The $\mathrm{MoNi}_{4}$ and $\mathrm{WNi}_{4}$ alloys were synthesized through a two-step method. First, sheet-like $\mathrm{Mo}(\mathrm{W})$-doped $\mathrm{Ni}(\mathrm{OH})_{2}$ precursors were 
a
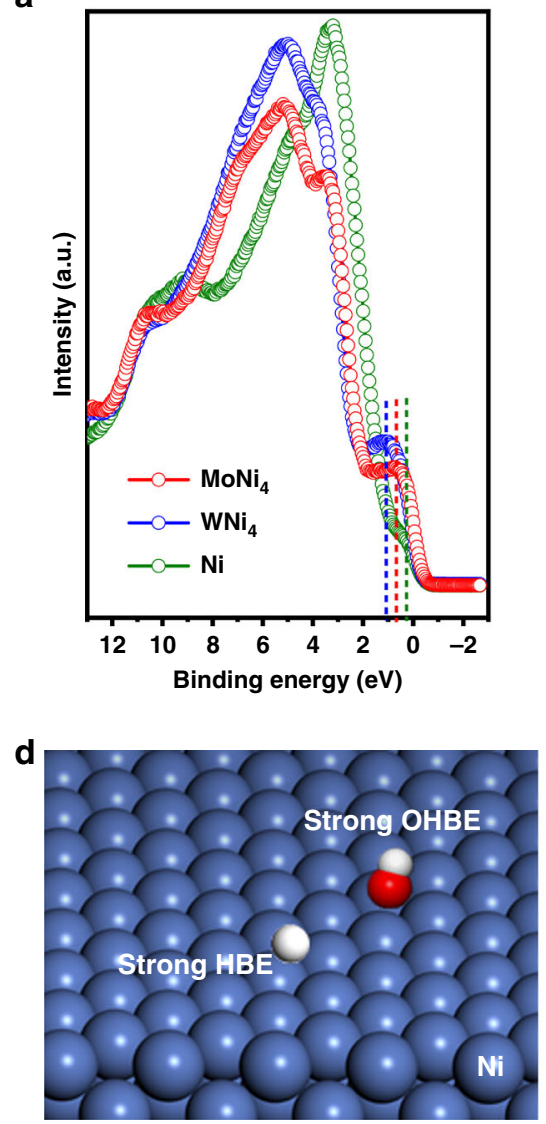

b

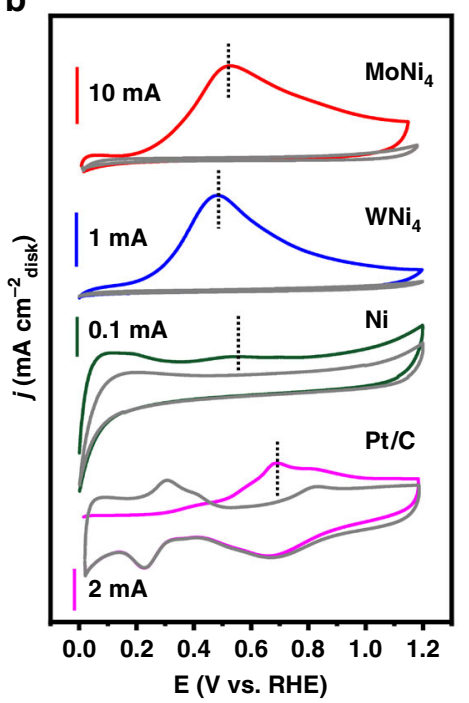

e

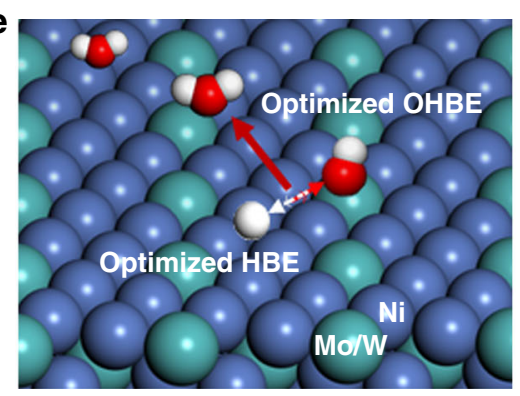

C
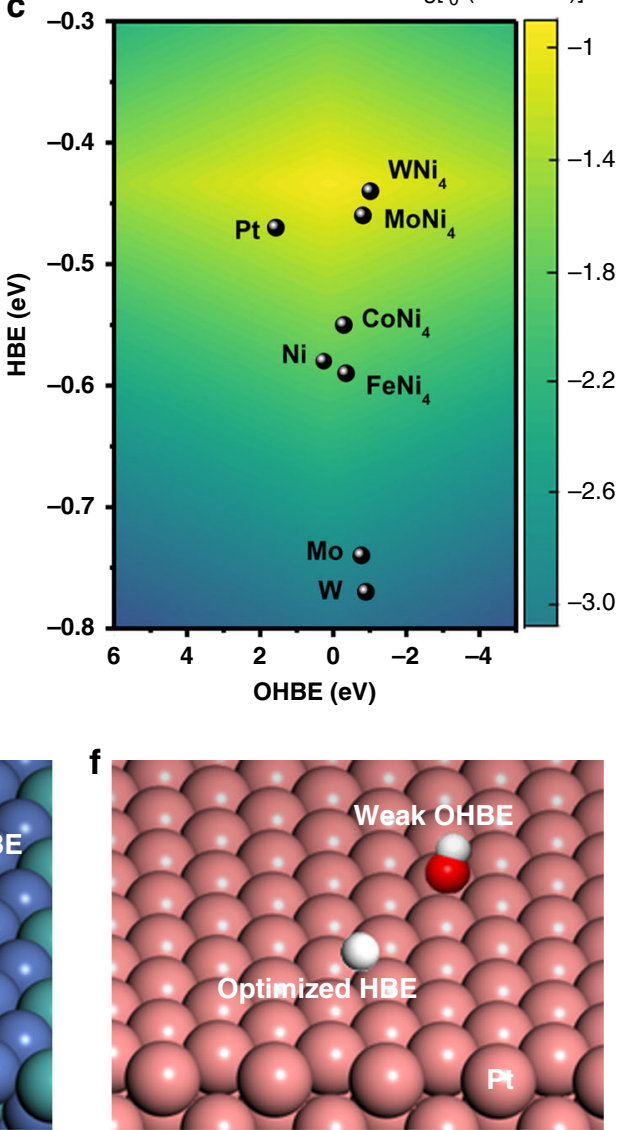

Fig. 5 HBE and OHBE. a UPS spectra of $\mathrm{MONi}_{4}, \mathrm{WNi}_{4}$, and freshly synthesized $\mathrm{Ni}$ catalysts. b CO-stripping measurements on $\mathrm{MoNi}_{4}$, $\mathrm{WNi}_{4}$, and freshly synthesized $\mathrm{Ni}$ and Pt/C catalysts. Sweep rate: $20 \mathrm{mV} \mathrm{s}^{-1}$. Rotation speed: 1600 r.p.m. The gray curves in $\mathbf{b}$ show the second cycle of the measurements. c The experimentally measured exchange current density normalized by ECSA, $\log \left(j_{0}\right)$, for the $\mathrm{HOR}$ in $0.1 \mathrm{M} \mathrm{KOH}$ on different catalysts plotted with the calculated $\mathrm{H}$ and $\mathrm{OH}$ binding energies. $\mathbf{d}$-f Schematic illustration of hydrogen and hydroxyl adsorption on freshly synthesized $\mathrm{Ni}_{1} \mathrm{Mo}(\mathrm{W}) \mathrm{Ni}_{4}$ alloys, and $\mathrm{Pt}$, respectively.

synthesized by microwave heating route. Briefly, $872 \mathrm{mg}$ of $\mathrm{Ni}\left(\mathrm{NO}_{3}\right)_{2} \cdot 6 \mathrm{H}_{2} \mathrm{O}$ and 96 $\mathrm{mg}\left(\mathrm{NH}_{4}\right)_{6} \mathrm{Mo}_{7} \mathrm{O}_{24} \cdot 4 \mathrm{H}_{2} \mathrm{O}$ (or $190 \mathrm{mg}\left(\mathrm{NH}_{4}\right)_{10} \mathrm{~W}_{12} \mathrm{O}_{41} \cdot x \mathrm{H}_{2} \mathrm{O}$ ) were dispersed into 3 $\mathrm{mL} \mathrm{H}_{2} \mathrm{O}$ in a $25 \mathrm{~mL}$ microwave glass vessel, followed by the addition of $1.2 \mathrm{~mL}$ $\mathrm{NH}_{3} \cdot \mathrm{H}_{2} \mathrm{O}$ and $15 \mathrm{~mL}$ ethylene glycol. After stirring for $20 \mathrm{~min}$, the mixture was irradiated in the microwave reactor (Monowave 450 , Anton Paar) at $200^{\circ} \mathrm{C}$ for 6 min with continuous magnetic stirring. After cooling to room temperature, the green powders were collected by centrifugation, washed, and dried for use. After that, the obtained $\mathrm{Mo}(\mathrm{W})$-doped $\mathrm{Ni}(\mathrm{OH})_{2}$ precursors were annealed in $\mathrm{H}_{2} / \mathrm{Ar}(5 /$ 95) atmosphere at 400 and $500{ }^{\circ} \mathrm{C}$ for $1 \mathrm{~h}$ with a heating rate of $3{ }^{\circ} \mathrm{C} \mathrm{min}-1$ to produce $\mathrm{MoNi}_{4}$ and $\mathrm{WNi}_{4}$ alloys, respectively ${ }^{47}$.

Synthesis of $\mathrm{CoNi}_{4}, \mathbf{F e N i}_{4}, \mathbf{N i}, \mathbf{M o}$, and $\mathbf{W}$. The $\mathrm{CoNi}_{4}$ and $\mathrm{FeNi}_{4}$ alloys were synthesized by the same method that was used for making $\mathrm{MoNi}_{4}$ alloy, while replacing the $\left(\mathrm{NH}_{4}\right)_{6} \mathrm{Mo}_{7} \mathrm{O}_{24} \cdot 4 \mathrm{H}_{2} \mathrm{O}$ with $218 \mathrm{mg} \mathrm{Co}\left(\mathrm{NO}_{3}\right)_{2} \cdot 6 \mathrm{H}_{2} \mathrm{O}$ and $303 \mathrm{mg} \mathrm{Fe}$ $\left(\mathrm{NO}_{3}\right)_{3} \cdot 9 \mathrm{H}_{2} \mathrm{O}$, respectively. The Ni nanopowder was synthesized through the same method for $\mathrm{MoNi}_{4}$ synthesis, but without adding $\left(\mathrm{NH}_{4}\right)_{6} \mathrm{Mo}_{7} \mathrm{O}_{24} \cdot 4 \mathrm{H}_{2} \mathrm{O}$ in the first step. The Mo metal was synthesized by annealing the $\mathrm{MoO}_{3-x}$ nanorods in $\mathrm{H}_{2} / \mathrm{Ar}$ $(5 / 95)$ atmosphere at $800^{\circ} \mathrm{C}$ for $2 \mathrm{~h}$, in which the $\mathrm{MoO}_{3-x}$ nanorods were prepared according to a previous work ${ }^{48}$. The $\mathrm{W}$ metal was synthesized by annealing the $\mathrm{WO}_{3} \cdot \mathrm{H}_{2} \mathrm{O}$ nanosheets in $\mathrm{H}_{2} / \mathrm{Ar}(5 / 95)$ atmosphere at $300^{\circ} \mathrm{C}$ for $1 \mathrm{~h}$ and subsequently at $850^{\circ} \mathrm{C}$ for $2 \mathrm{~h}$, in which the $\mathrm{WO}_{3} \cdot \mathrm{H}_{2} \mathrm{O}$ nanosheets were prepared according to the previous work ${ }^{49}$.

Characterization. SEM (Zersss Supra 40) and TEM (Hitachi H7700) were performed to investigate the morphology of the samples. The STEM and HRTEM images, and EDX elemental mappings, were obtained on Atomic-Resolution Analytical Microscope (JEM-ARM 200F) with an acceleration voltage of $200 \mathrm{kV}$. $\mathrm{N}_{2}$ adsorption/desorption analysis was taken on an ASAP 2020 (Micromeritics, USA) at $77 \mathrm{~K}$. XRD was conducted on a Philips X'Pert Pro Super with $\mathrm{Cu} \mathrm{Ka}$ radiation $(\lambda=1.541841 \AA$ ). ICP-AES results were taken by Optima 7300 DV instrument. The UPS was conducted on the BL10B beamline and XPS was conducted on the BL11U beamline of National Synchrotron Radiation Laboratory in Hefei (China).

XAFS measurements. The XAFS spectra (Ni K-edge, Mo K-edge, and $\mathrm{W} \mathrm{L}_{3}$-edge) were collected at 1W1B station in Beijing Synchrotron Radiation Facility. The $k^{3}$ weighted EXAFS spectra were obtained by subtracting the post-edge background from the overall absorption, followed by normalizing with respect to the edge-jump step. Next, the real $(R)$ space is obtained by Fourier transformation of $k^{3}$-weighted $\chi(k)$ data with a Hanning window $\left(\mathrm{d} k: 1.0 \AA^{-1}\right)$ to separate the signal contributions from different coordination shells. Least-squares curve parameter fitting was executed using the ARTEMIS module of the IFEFFIT software packages ${ }^{50}$ to study the quantitative structural parameters around the central atoms.

Electrochemical measurements. The HOR electrochemical measurements were conducted by a conventional three-electrode system on the electrochemical workstation (IM6ex, Zahner-Elektrik). An RDE with glassy carbon (PINE with a diameter of $5.00 \mathrm{~mm}$ and a disk area of $0.196 \mathrm{~cm}^{2}$ ) was applied as the working electrode. The $\mathrm{Ag} / \mathrm{AgCl}(3.5 \mathrm{M} \mathrm{KCl})$ electrode and carbon rod were used as reference electrode and counter electrode, respectively. The RHE calibration was performed in high-purity $\mathrm{H}_{2}$-saturated $0.1 \mathrm{M} \mathrm{KOH}$ with a Pt foil as the working electrode $\left(E_{\mathrm{RHE}}=E_{\mathrm{Ag} / \mathrm{AgCl}}+0.967 \mathrm{~V}\right)$.

To make working electrodes, $10 \mathrm{mg}$ catalyst powders were dispersed in $920 \mu \mathrm{L}$ ethanol with $80 \mu \mathrm{L}$ Nafion ( $5 \mathrm{wt} \%$ ), which yield a homogeneous ink by ultrasonication. Then, $10 \mu \mathrm{l}$ catalyst ink was pipetted onto a glassy carbon electrode, resulting in a catalyst loading of $\sim 0.5 \mathrm{mg} \mathrm{cm}^{-2}$. Before HOR measurements, $0.1 \mathrm{M} \mathrm{KOH}$ electrolyte was bubbled with high-purity $\mathrm{H}_{2}$ gas for 30 $\min$. The electrodes were pre-cycled between -1.1 and $-0.75 \mathrm{~V}$ versus $\mathrm{Ag} / \mathrm{AgCl}$ with a sweep rate of $10 \mathrm{mV} \mathrm{s}^{-1}$ for 10 cycles to reach a stable state, then HOR polarization curves were collected with a sweep rate of $0.5 \mathrm{mV} \mathrm{s}^{-1}$. The electrochemical impedance spectroscopy measurement was carried out at $30 \mathrm{mV}$ overpotential and an amplitude of the sinusoidal voltage of $5 \mathrm{mV}$ (frequency range: $100 \mathrm{kHz}-40 \mathrm{mHz}$ ). For stability test, the catalysts were loaded onto clean carbon 
fiber paper (catalyst loading: $\sim 2 \mathrm{mg} \mathrm{cm}^{-2}$ ) and used as a working electrode to perform chronoamperometry experiments at a constant potential of $60 \mathrm{mV}$ versus RHE ( $i R$ free).

The kinetic current density was calculated by Koutecky-Levich equation. The measured overall HOR current density $(j)$ can be divided into kinetic current density $\left(j_{k}\right)$ and diffusion current density $\left(j_{\mathrm{d}}\right)$ based on the Koutecky-Levich equation:

$$
\frac{1}{j}=\frac{1}{j_{\mathrm{k}}}+\frac{1}{j_{\mathrm{d}}},
$$

where $j_{\mathrm{d}}$ for a rotating-disk electrode can be described by the Levich equation:

$$
j_{\mathrm{d}}=0.62 n F D^{3 / 2} v^{-1 / 6} C_{0} \omega^{1 / 2}=B C_{0} \omega^{1 / 2},
$$

in which $n$ is the number of electrons involved in the oxidation reaction, $F$ is the Faraday constant, $D$ is the diffusion coefficient of the reactant, $v$ is the viscosity of electrolyte, $C_{0}$ is the solubility of $\mathrm{H}_{2}$ in the electrolyte, $B$ is the Levich constant, and $\omega$ is the rotating speed.

The exchange current $\left(j_{0}\right)$ can also be obtained by fitting the linear portion of the Tafel plots, where the Bulter-Volmer equation can be converted to Tafel equation:

$$
\eta=\log \left(j_{0}\right)+b \times \log (j) .
$$

$\mathrm{CO}$ stripping was performed by holding the electrode potential at $0.1 \mathrm{~V}$ versus RHE for $10 \mathrm{~min}$ in the purged $\mathrm{CO}$ to adsorb $\mathrm{CO}$ on the metal surface, followed by Ar purging for another $30 \mathrm{~min}$ to remove residual $\mathrm{CO}$ in the electrolyte. The COstripping current was obtained via cyclic voltammetry in a potential region from 0 to $1.2 \mathrm{~V}$ at a sweep rate of $20 \mathrm{mV} \mathrm{s}^{-1}$.

DFT calculations. All the computations were performed by using the Vienna ab initio Simulation Package ${ }^{51}$ at the spin-polarized DFT level. The electronic exchange and correlation effects were described with the Perdew-Burke-Ernzerhof formalism ${ }^{52}$ within a generalized gradient approximation. The interaction between the ion cores and valence electrons was simulated by the all-electron projectoraugmented wave ${ }^{53}$. The exchange correction treated for the transitional metals was based on the previous literatures, which includes the same metals as ours for reliability and comparability $33,34,54$. A kinetic cut-off energy of $500 \mathrm{eV}$ was employed for the plane-wave expansion and a Gaussian electron smearing of $0.1 \mathrm{eV}$ was used. The $(3 \times 3)-\mathrm{Ni}(111),(3 \times 3)-\mathrm{Mo}(110),(3 \times 3)-\mathrm{W}(110),(3 \times 3)-\mathrm{Pt}(111)$, $(1 \times 1)-\mathrm{CoNi}_{4}(111),(1 \times 1)-\mathrm{FeNi}_{4}(111),(1 \times 1)-\mathrm{MoNi}_{4}(211)$, and $(1 \times 1)-$

$\mathrm{WNi}_{4}(211)$ slabs with four layers and $15 \AA$ vacuum layer were modeled to simulate the explored surfaces of metals and alloys. The convergence criteria for the forces and energy were $10^{-4} \mathrm{eV}$ and $0.02 \mathrm{eV} \AA^{-1}$, respectively, with the bottom layer fixed, while other layers relaxed during geometry optimization. These convergence criteria were chosen according to the previous literatures to ensure the accuracy ${ }^{34,54}$. The $9 \times 9 \times 9$ and $5 \times 5 \times 1$ Monkhorst-Pack k-point grids were sampled for the bulk and slab structures, separately.

The adsorption energies of hydrogen and hydroxyl species with the explored catalysts were calculated according to $E_{\mathrm{H} \text {-ads }}=E_{\mathrm{H} @ \text { cat. }}-E_{\text {cat. }}-E_{H}$ and $E_{\mathrm{OH}-\text { ads }}=$ $E_{\mathrm{OH} @ \mathrm{cat}}-E_{\mathrm{cat}}-E_{\mathrm{OH}}$, where $E_{\mathrm{H} @ \mathrm{cat}}$ and $E_{\mathrm{OH} @ \mathrm{cat}}$. represent the energy of metals or alloys slabs with the adsorbed hydrogen and hydroxyl species, while $E_{\text {cat. }}, E_{\mathrm{H}}$, and $E_{\mathrm{OH}}$ stand for the energies of the metals or alloys slabs, the hydrogen atoms, and hydroxyl species, respectively. A more negative $E_{\mathrm{H} \text {-ads }}$ or $E_{\mathrm{OH} \text {-ads }}$ indicates a larger binding energy.

\section{Data availability}

The data that support the findings of this study are available from the corresponding authors upon request.

Received: 4 February 2020; Accepted: 25 August 2020;

Published online: 22 September 2020

\section{References}

1. Daud, W. R. W. et al. PEM fuel cell system control: a review. Renew. Energy 113, 620-638 (2017).

2. Chattot, R. et al. Surface distortion as a unifying concept and descriptor in oxygen reduction reaction electrocatalysis. Nat. Mater. 17, 827 (2018).

3. Setzler, B. P., Zhuang, Z., Wittkopf, J. A. \& Yan, Y. Activity targets for nanostructured platinum-group-metal-free catalysts in hydroxide exchange membrane fuel cells. Nat. Nano 11, 1020-1025 (2016).

4. Zhao, Y. et al. Few-layer graphdiyne doped with sp-hybridized nitrogen atoms at acetylenic sites for oxygen reduction electrocatalysis. Nat. Chem. 10, 924 (2018).

5. Qu, Y. et al. Direct transformation of bulk copper into copper single sites via emitting and trapping of atoms. Nat. Catal. 1, 781-786 (2018).
6. Durst, J. et al. New insights into the electrochemical hydrogen oxidation and evolution reaction mechanism. Energy Environ. Sci. 7, 2255-2260 (2014).

7. Sheng, W., Gasteiger, H. A. \& Shao-Horn, Y. Hydrogen oxidation and evolution reaction kinetics on platinum: acid vs alkaline electrolytes. $J$. Electrochem. Soc. 157, B1529-B1536 (2010).

8. Kundu, M. K., Bhowmik, T., Mishra, R. \& Barman, S. Platinum nanostructure/ nitrogen-doped carbon hybrid: enhancing its base media HER/HOR activity through bi-functionality of the catalyst. ChemSusChem 11, 2388-2401 (2018).

9. Qiu, Y. et al. BCC-phased PdCu alloy as a highly active electrocatalyst for hydrogen oxidation in alkaline electrolytes. J. Am. Chem. Soc. 140, 16580-16588 (2018).

10. Zheng, J., Sheng, W., Zhuang, Z., Xu, B. \& Yan, Y. Universal dependence of hydrogen oxidation and evolution reaction activity of platinum-group metals on $\mathrm{pH}$ and hydrogen binding energy. Sci. Adv. 2, e1501602 (2016).

11. Sheng, W. et al. Correlating hydrogen oxidation and evolution activity on platinum at different $\mathrm{pH}$ with measured hydrogen binding energy. Nat. Commun. 6, 5848 (2015).

12. Ohyama, J., Sato, T., Yamamoto, Y., Arai, S. \& Satsuma, A. Size specifically high activity of Ru nanoparticles for hydrogen oxidation reaction in alkaline electrolyte. J. Am. Chem. Soc. 135, 8016-8021 (2013).

13. Lu, S. \& Zhuang, Z. Investigating the influences of the adsorbed species on catalytic activity for hydrogen oxidation reaction in alkaline electrolyte. J. Am. Chem. Soc. 139, 5156-5163 (2017).

14. St. John, S. et al. Platinum and palladium overlayers dramatically enhance the activity of ruthenium nanotubes for alkaline hydrogen oxidation. ACS Catal. 5, 7015-7023 (2015).

15. Alia, S. M., Pivovar, B. S. \& Yan, Y. Platinum-coated copper nanowires with high activity for hydrogen oxidation reaction in base. J. Am. Chem. Soc. 135, 13473-13478 (2013)

16. Okubo, K., Ohyama, J. \& Satsuma, A. Surface modification of Pt nanoparticles with other metals boosting the alkaline hydrogen oxidation reaction. Chem. Commun. 55, 3101-3104 (2019).

17. Wang, L., Mahoney, E. G., Zhao, S., Yang, B. \& Chen, J. G. Low loadings of platinum on transition metal carbides for hydrogen oxidation and evolution reactions in alkaline electrolytes. Chem. Commun. 52, 3697-3700 (2016).

18. Jervis, R. et al. Hydrogen oxidation on PdIr/C catalysts in alkaline media. J. Electrochem. Soc. 161, F458-F463 (2014).

19. Cong, Y. et al. Uniform $\mathrm{Pd}_{0.33} \mathrm{Ir}_{0.67}$ nanoparticles supported on nitrogendoped carbon with remarkable activity toward the alkaline hydrogen oxidation reaction. J. Mater. Chem. A 7, 3161-3169 (2019).

20. St. John, S., Atkinson, R. W., Unocic, R. R., Zawodzinski, T. A. \& Papandrew A. B. Ruthenium-alloy electrocatalysts with tunable hydrogen oxidation kinetics in alkaline electrolyte. J. Phys. Chem. C 119, 13481-13487 (2015).

21. Wang, Y. et al. Pt-Ru catalyzed hydrogen oxidation in alkaline media: oxophilic effect or electronic effect? Energy Environ. Sci. 8, 177-181 (2015).

22. Sheng, W., Myint, M., Chen, J. G. \& Yan, Y. Correlating the hydrogen evolution reaction activity in alkaline electrolytes with the hydrogen binding energy on monometallic surfaces. Energy Environ. Sci. 6, 1509-1512 (2013).

23. Li, J. et al. Experimental proof of the bifunctional mechanism for the hydrogen oxidation in alkaline media. Angew. Chem. Int. Ed. 56, 15594-15598 (2017).

24. Liu, E. et al. Unifying the hydrogen evolution and oxidation reactions kinetics in base by identifying the catalytic roles of hydroxyl-water-cation adducts. $J$. Am. Chem. Soc. 141, 3232-3239 (2019).

25. Schmidt, T., Ross, P. Jr \& Markovic, N. Temperature dependent surface electrochemistry on Pt single crystals in alkaline electrolytes: Part 2. The hydrogen evolution/oxidation reaction. J. Electroanal. Chem. 524, 252-260 (2002).

26. Zheng, J., Nash, J., Xu, B. \& Yan, Y. Perspective-towards establishing apparent hydrogen binding energy as the descriptor for hydrogen oxidation/evolution reactions. J. Electrochem. Soc. 165, H27-H29 (2018).

27. Strmcnik, D. et al. Improving the hydrogen oxidation reaction rate by promotion of hydroxyl adsorption. Nat. Chem. 5, 300 (2013).

28. Bacon, F. T. The high pressure hydrogen-oxygen fuel cell. Ind. Eng. Chem. 52, 301-303 (1960)

29. $\mathrm{Ni}, \mathrm{W}$. et al. $\mathrm{Ni}_{3} \mathrm{~N}$ as an active hydrogen oxidation reaction catalyst in alkaline medium. Angew. Chem. Int. Ed. 58, 7445-7449 (2019).

30. Yang, F. et al. Boosting hydrogen oxidation activity of $\mathrm{Ni}$ in alkaline media through oxygen-vacancy-rich $\mathrm{CeO}_{2} / \mathrm{Ni}$ heterostructures. Angew. Chem. Int. Ed. 58, 14179-14183 (2019).

31. Yang, Y. et al. Enhanced electrocatalytic hydrogen oxidation on $\mathrm{Ni} / \mathrm{NiO} / \mathrm{C}$ derived from a Ni-based MOF. Angew. Chem. Int. Ed. 58, 10644-10649 (2019).

32. Kabir, S. et al. Platinum group metal-free NiMo hydrogen oxidation catalysts: high performance and durability in alkaline exchange membrane fuel cells. $J$. Mater. Chem. A 5, 24433-24443 (2017).

33. Sheng, W. et al. Non-precious metal electrocatalysts with high activity for hydrogen oxidation reaction in alkaline electrolytes. Energy Environ. Sci. 7, 1719-1724 (2014) 
34. Zhuang, Z. et al. Nickel supported on nitrogen-doped carbon nanotubes as hydrogen oxidation reaction catalyst in alkaline electrolyte. Nat. Commun. 7, 10141 (2016)

35. Lu, S., Pan, J., Huang, A., Zhuang, L. \& Lu, J. Alkaline polymer electrolyte fuel cells completely free from noble metal catalysts. Proc. Natl Acad. Sci. USA 105, 20611-20614 (2008).

36. Justi, E. W. \& Winsel, A. W. The DSK system of fuel cell electrodes. J. Electrochem. Soc. 108, 1073-1079 (1961).

37. Helm, M. L., Stewart, M. P., Bullock, R. M., DuBois, M. R. \& DuBois, D. L. A synthetic nickel electrocatalyst with a turnover frequency above $100,000 \mathrm{~s}^{-1}$ for $\mathrm{H}_{2}$ production. Science 333, 863-866 (2011).

38. Schilter, D., Fuller, A. L. \& Gray, D. L. Nickel-molybdenum and nickeltungsten dithiolates: hybrid models for hydrogenases and hydrodesulfurization. Eur. J. Inorg. Chem. 2015, 4638-4642 (2015).

39. Mao, J. et al. Design of ultrathin Pt-Mo-Ni nanowire catalysts for ethanol electrooxidation. Sci. Adv. 3, e1603068 (2017).

40. Yang, Y. et al. Versatile nickel-tungsten bimetallics/carbon nanofiber catalysts for direct conversion of cellulose to ethylene glycol. Green. Chem. 18, 3949-3955 (2016).

41. Funke, H., Scheinost, A. \& Chukalina, M. Wavelet analysis of extended X-ray absorption fine structure data. Phys. Rev. B 71, 094110 (2005).

42. Berlich, A., Liu, Y. C. \& Morgner, H. Evaporation of Ni and carbon containing species onto $\mathrm{NiO} / \mathrm{Ni}$ as case study for metal support catalysts investigated by metastable induced electron spectroscopy (MIES). Radiat. Phys. Chem. 74, 201-209 (2005).

43. Lawniczak-Jablonska, K. \& Heinonen, M. Influence of sputtering on the valence band of Mo, Ni and $\mathrm{MoNi}_{3}$ alloy. J. Phys. F 18, 2451 (1988).

44. Chen, Z. et al. Tailoring the d-band centers enables $\mathrm{Co}_{4} \mathrm{~N}$ nanosheets to be highly active for hydrogen evolution catalysis. Angew. Chem. Int. Ed. 57, 5076-5080 (2018).

45. Hori, Y. \& Murata, A. Electrochemical evidence of intermediate formation of adsorbed $\mathrm{CO}$ in cathodic reduction of $\mathrm{CO}_{2}$ at a nickel electrode. Electrochim. Acta 35, 1777-1780 (1990).

46. Cuesta, A. \& Gutiérrez, C. Study by potential-modulated reflectance spectroscopy of the electroadsorption of $\mathrm{CO}$ on $\mathrm{Ni}$ in alkaline medium. $J$. Electroanal. Chem. 382, 153-159 (1995).

47. Tian, X., Zhao, P. \& Sheng, W. Hydrogen evolution and oxidation: mechanistic studies and material advances. Adv. Mater. 31, 1808066 (2019).

48. $\mathrm{Li}, \mathrm{B}$. et al. Phase and morphological control of $\mathrm{MoO}_{3-x}$ nanostructures for efficient cancer theragnosis therapy. Nanoscale 9, 11012-11016 (2017).

49. Zhang, N. et al. Oxide defect engineering enables to couple solar energy into oxygen activation. J. Am. Chem. Soc. 138, 8928-8935 (2016).

50. Ravel, B. \& Newville, M. ATHENA, ARTEMIS, HEPHAESTUS: data analysis for X-ray absorption spectroscopy using IFEFFIT. J. Synchrot. Radiat. 12, 537-541 (2005).

51. Hafner, J. Ab-initio simulations of materials using VASP: density-functional theory and beyond. J. Comput. Chem. 29, 2044-2078 (2008).

52. Ernzerhof, M. \& Scuseria, G. E. Assessment of the Perdew-Burke-Ernzerhof exchange-correlation functional. J. Chem. Phys. 110, 5029-5036 (1999).

53. Kresse, G. \& Joubert, D. From ultrasoft pseudopotentials to the projector augmented-wave method. Phys. Rev. B 59, 1758 (1999).

54. Zhang, J. et al. Efficient hydrogen production on $\mathrm{MoNi}_{4}$ electrocatalysts with fast water dissociation kinetics. Nat. Commun. 8, 15437 (2017).

\section{Acknowledgements}

We acknowledge the funding support from the National Natural Science Foundation of China (Grants 21521001, 21431006, 21225315, 21321002, 91645202, 51702312, and
21975237), the Users with Excellence and Scientific Research Grant of Hefei Science Center of CAS (2015HSCUE007), the Key Research Program of Frontier Sciences, CAS (Grant QYZDJ-SSW-SLH036), the National Basic Research Program of China (Grants 2014CB931800 and 2018YFA0702001), the Chinese Academy of Sciences (Grants KGZD-EW-T05 and XDA090301001), the Strategic Priority Research Program of the Chinese Academy of Sciences (XDA21000000), the Fundamental Research Funds for the Central Universities (WK2060190045 and WK2340000076), and the Recruitment Program of Global Youth Experts. Z.-Y.Y. acknowledges the Anhui Provincial Natural Science Foundation (Grant 1908085QB60). We acknowledge the BL10B beamline of the National Synchrotron Radiation Laboratory in Hefei (China) This work was partially carried out at the USTC Center for Micro and Nanoscale Research and Fabrication.

\section{Author contributions}

M.-R.G., Y.D., and S.-H.Y. conceived the idea. M.-R.G. and S.-H.Y. supervised the project. Y.D., Z.-Y.Y., and C.-T.Z. performed the experiments, and collected and analyzed the data. L.Y. and J.J. carried out the DFT calculations. X.-S.Z., H.-.H.D., and J.-F.Z. performed UPS and XPS measurements. L.S. performed the HAADF-STEM measurements. L.-R.Z. and C.G. collected and analyzed the XANES data. X.-T.Y., F.-Y.G., X.-L.Z., X.Y., and R.L. assisted with the experiments and characterizations. M.-R.G., Y.D., and S.H.Y. co-wrote the manuscript. All authors discussed the results and commented on the manuscript.

\section{Competing interests}

The authors declare no competing interests.

\section{Additional information}

Supplementary information is available for this paper at https://doi.org/10.1038/s41467020-18585-4.

Correspondence and requests for materials should be addressed to M.-R.G. or S.-H.Y.

Peer review information Nature Communications thanks the anonymous reviewers for their contributions to the peer review of this work. Peer review reports are available.

Reprints and permission information is available at http://www.nature.com/reprints

Publisher's note Springer Nature remains neutral with regard to jurisdictional claims in published maps and institutional affiliations.

Open Access This article is licensed under a Creative Commons Attribution 4.0 International License, which permits use, sharing, adaptation, distribution and reproduction in any medium or format, as long as you give appropriate credit to the original author(s) and the source, provide a link to the Creative Commons license, and indicate if changes were made. The images or other third party material in this article are included in the article's Creative Commons license, unless indicated otherwise in a credit line to the material. If material is not included in the article's Creative Commons license and your intended use is not permitted by statutory regulation or exceeds the permitted use, you will need to obtain permission directly from the copyright holder. To view a copy of this license, visit http://creativecommons.org/ licenses/by/4.0/.

(C) The Author(s) 2020 